Jurnal Keuangan dan Perbankan, Vol.19, No.3 September 2015, hlm. 497-504

Terakreditasi SK. No. 040/P/2014

http://jurkubank.wordpress.com

\title{
DUKUNGAN OPT-OUT DAN PERSEPSI NILAI E-BANKING
}

\author{
Ni Made Purnami \\ Prodi M anajemen Fakultas Ekonomi dan Bisnis Universitas Udayana
}

\begin{abstract}
The aim of this study was to determine the effect of perceived firm commitment to privacy and trust in technology on perceived value from the firm with opt-out support as moderating variable. The study was conducted in D enpasar City with sample size of 120 ebanking user. Sample was determined by purposive sampling and data were collected by using questionnaires distributed directly. The data were processed with $M$ oderate R egression A nalysis (M RA). Theresults of this study indicatethat perceived firm commitment to privacy and trust in technology is positively affect perceived valuefrom thefirm. 0 pt-out support aresignificantly moderatetherelationship trust in technology and perceived valuefrom thefirm, and the results show a negatif coefficient, which means that theincomelevel weagken theinfluence of trust in technol ogy on perceived valuefrom thefirm.
\end{abstract}

Keywords: opt out support and valuefrom thefirm.

\section{PENDAHULUAN}

Internet dalam kehidupan sehari-hari digunakan oleh masyarakat untuk memperoleh informasi, berkomunikasi maupun digunakan sebagai sarana hiburan. Piranti digital seperti smartphone, tablet serta alat komunikasi lainnya telah mengubah perilaku belanja masyarakat. Dibandingkan dengan belanja tatap muka tradisional, belanja online menawarkan beberapa kel ebi han yang unik yaitu pilihan yang lebih banyak, banyak tersedia informasi produk, dan tidak ada batasan temporal dan spasial (Wen et al. 2011).
Perkembangan belanja online disatu sisi ternyata menimbulkan kekhawatiran terkait dengan penggunaan teknologi komputerisasi serta dari keterbukaan internet sebagai media komunikasi dan media transaksi (Thatcher et al, 2007; Yao \& Liao, 2011). Chi, Yeh \& Hung (2012) menyatakan bahwa penggunaan internetmenimbulkan kecemasan akan risiko yang berhubungan dengan transaski online. Internet dan perkembangan pasar global dengan berbagai manfaat menarik dalam bertransaksi juga berpotensi disalahgunakan seperti pelanggaran privasi dan penipuan (Armesh et al, 2010). Penelitian ini dilatarbelakangi oleh adanya motivasi konsumen

Korespondensi dengan Penulis:

Ni Made Purnami: Telp: -

E-mail: made.purnami@yahoo.com 
online untuk mengurangi kekhawatiran dalam transaksi online sebagai reaksi terhadap kekhawatiran privasi konsumen, kepercayaan konsumen terhadap teknologi sebagai rekasi terhadap berkembangnya teknologi informasi. Masalah privasi seperti pengisian biodata menjadi menjadi faktor kunci yang menghalangi konsumen belanja melalui internet. Chen \& Chou (2012) menyatakan bahwa kepercayaan dan niat membeli kembali memiliki hubungan yang positif.

Komunikasi pemasaran melalui media online telah dilakukan oleh banyak perusahaan. E-mail telah berkembang menjadi salah satu sarana pemasaran online. Studi tentang iklan, merek dan manajer pemasaran menemukan bahwa hampir setengah dari semua pelanggan $B 2 B$ dan $B 2 C$ yang disurvey menggunakan pemasaran $e$-mail untuk menjangkau pelanggan (Kotler \& Armstrong, 2008:250). Agar tidak menggangu konsumen dengan mengirimkan e-mail pemasaran yang tidak diinginkan, perusahaan harus meminta ijin kepada pelanggan untuk menawarkan pemasaran email. Perusahaan harus memberi tahu penerima bagaimana cara "memilih masuk (opt-in)" atau memilih keluar (optout)" promosi email setiap saat (Kotler \& Armstrong, 2008:251).

Dukungan opt-out, dimana konsumen memperbolehkan untuk berbagi informasi konsumen tetapi konsumen harus memungkinkan untuk memilih keluar (opt-out) saat dihubungi oleh penjual. Dukungan opt-out konsumen merupakan keyakinan konsumen bahwa pemasar diijinkan menggunakan informasi pribadi seperti alamat tinggal, alamat kerja, alamat email tanpa persetujuan sebelumnya selama setiap komunikasi memungkinkan konsumen mempunyai kesempatan untuk mencegah kontak lebih lanjut dengan menghapus diri dari daftar kontak (Johnson, 2014).

Industri perbankan yang telah menerapkan e-banking di Indonesia telah mengumumkan pada halaman web perusahaan mengenai kebijakan privasi dan pengamanan (online privacy and security).
Kebijakan tersebut seperti kebijakan privasi yang menyatakan bahwa bank tidak menjual, menukar ataupun memperlihatkan segala informasi yang berkaitan dengan nasabah dan pengguna $e$-banking. Bank pun telah menyatakan sistem pengamanan yang telah mereka gunakan dalam melindungi akses dan transaksi konsumen di internet banking. Komiten bank terhadap privasi dan pengamanan tentunya tidak lepas dari ancaman penipuan dari pihak yang tidak betanggung jawab. Kepercayaan dan kemampuan nasabah akan teknologi juga mempengaruhi persepsi nasabah di dalam menggunakan layanan e-banking. Sebuah situs web yang dirancang dengan baik juga ditemukan untuk membantu dalam memfasilitasi penggunaan lebih mudah dan juga meminimalkan kekhawatiran risiko yang dirasakan mengenai penggunaan internet banking (Kesharwani \& Shailendra, 2012). Keberhasilan implementasi m-banking dipengaruhi oleh beberapa faktor, diantaranya adalah tingkat adopsi konsumen dalam penggunaan ponsel untuk saluran perbankan, kebutuhan konsumen untuk perbankan online serta kualitas layanan telekomunikasi (Ketkar et al. 2012).

Penelitian sebelumnya yang berkaitan dengan layanan online pada umumnya lebih menekankan pada hubungan antara kualitas pelayanan dan kepuasan pelanggan, niat melakukan pembelian dan loyalitas konsumen misalnya penelitian Carlson \& O,cos, 2011). Penelitian ini lebih jauh memahami bagaimana implikasi dari pengalaman penggunaan internet banking dari konsumen sebagai awal dalam membangun loyalitas pelanggan. Menganalisis bagaimana pandangan konsumen terhadap privasi pribadi mereka yang telah dituliskan dalam pengisian biodata dalam pengajuan internet banking akan dilindungi oleh pihak bank yang berdampak pada persepsi konsumen. Kepercayaan konsumen akan penggunakan teknologi juga menjadi bagian dalam penelitian ini. Persepsi komitmen akan privasi konsumen serta kepercayaan terhadap teknologi yang berpengaruh pada per- 
sepsi konsumen dapat diperkuat atau diperlemah oleh variabel dukungan opt out dari perusahaan.

Penelitian ini bertujuan untuk mengetahui 1) pengaruh komitment bank terhadap privasi konsumen terhadap persepsi nilai pelanggan dari layanan e-banking; 2) pengaruh kepercayaan konsumen akan teknologi terhadap persepsi nilai pelanggan dari layanan e-banking; dan 3) untuk mengetahui peran dukungan opt-out dalam memoderasi pengaruh kepercayaan akan teknologi terhadap persepsi nilai dari layanan e-banking.

Persepsi nilai oleh konsumen tidak hanya ditimbulkan dari proses transaksi, tetapi juga dari kemitraan interaktif antara perusahaan dan pelanggan, Vagra dan Lush (dalam Johnson 2014). Persepsi bahwa perusahaan menjaga informasi pribadi konsumen berpengaruh positif terhadap persepsi privasi (Dinev et al. 2013). Konsumen juga melindungi diri mereka dari kekhawatiran pelayanan online dengan mencari perusahaan yang mempunyai reputasi baik (Porter \& Donthu, 2008); (Yap et al, 2010). Komitment bank terhadap privasi konsumen berpengaruh positif terhadap persepsi nilai pelanggan dari layanan e-banking (Johnson, 2014).

Konsumen yang familiar dalam menggunakan internet mempunyai tingkat kepercayaan yang lebih tinggi terhadap internet dibandingkan konsumen yang tidak terbiasa menggunakan internet. Kepercayaan terhadap internet berpengaruh positif terhadap sikap dalam menggunakan internet banking (Grabner \& Sonja, 2008). Hasil penelitian Armesh et al (2010) menyatakan bahwa terdapat hubungan yang signifikan antara kepercayaan online dengan loyalitas konsumen. Kepercayaan di media online juga berhubungan positif dengan niat beli (Benedictus et al, 2010). Liu \& Hung (2010) mengemukakan bahwa toko online harus menyesuaikan lingkungan transaksi online untuk memaksimalkan kepercayaan serta loyalitas pelanggan.

Kepercayaan dalam teknologi mengacu pada kemampuan konsumen dalam penggunaan kom- puter secara teknis. Penelitian sebelumnya di perbankan online menunjukkan bahwa kepercayaan terhadap teknologi memiliki pengaruh yang positif terhadap perspsi nilai (Johnson, 2014). Hasil penelitian Johnson (2007) juga menyatakan bahwa kepercayaan dalam teknologi perbankan online adalah mediator penting dalam meningkatkan frekuensi transaksi konsumen dan nilai dari perbankan online.

Konsumen yang mendukung prinsip opt out lebih mungkin untuk melihat kepercayaan dari teknologi sebagai sumber nilai dari hubungan online mereka. Dalam konteks online, kontrol pengguna diartikan sebagai kemampuan pengguna untuk mengontrol aliran komunikasi dua arah (Mc Millan dan Hwang, 2002) dan sebagai control pengguna melalui arus informasi (Liu, 2003).

Berdasarkan uraian tersebut maka hipotesis dalam penelitian ini adalah

$\mathrm{H}_{1}$ : Persepsi komitmen privasi berpengaruh positif terhadap persepsi nilai pelanggan dari layanan $e$-banking

$\mathrm{H}_{2}$ : Kepercayaan teknologi berpengaruh positif terhadap persepsi nilai pelanggan dari layanan e-banking

$\mathrm{H}_{3}$ : Dukungan opt-out memoderasi pengaruh kepercayaan akan teknologi terhadap persepsi nilai dari layanan e-banking.

\section{METODE}

Rancangan penelitian digunakan untuk mengetahui pengaruh persepsi komitment privasi dari bank yang memberi layanan e-banking dan kepercayaan teknologi persepsi nilai e-banking. Penelitian ini juga menganalisis lebih jauh bagaimana peran dukungan opt-out sebagai variabel moderasi variabel kepercayaan akan terknologi dan persepsi nilai. Penelitian ini dilakukan di Kota Denpasar dengan populasi nasabah yang telah menggunakan fasilitas e-banking. Jumlah sampel sebanyak 10 kali jumlah indikator yaitu 120 responden. Kuesioner 
digunakan sebagai instrument dalam pengumpulan data dalam penelitian ini.

Teknik analisis data yang digunakan dalam penelitian ini adalah teknik analisis regresi moderasi yaitu uji interaksi. Menurut Ghozali (2014: 243) terdapat uji interaksi untuk menguji regresi dengan variabel moderating. Uji interaksi ini digunakan untuk mengukur peran variabel moderasi apakah memperkuat atau memperlemah posisi variabel bebas. Persamaan rumus Moderated Reggression Analysis (MRA) untuk menguji hipotesis atau model matematis hubungan antar variabel adalah sebagai berikut.

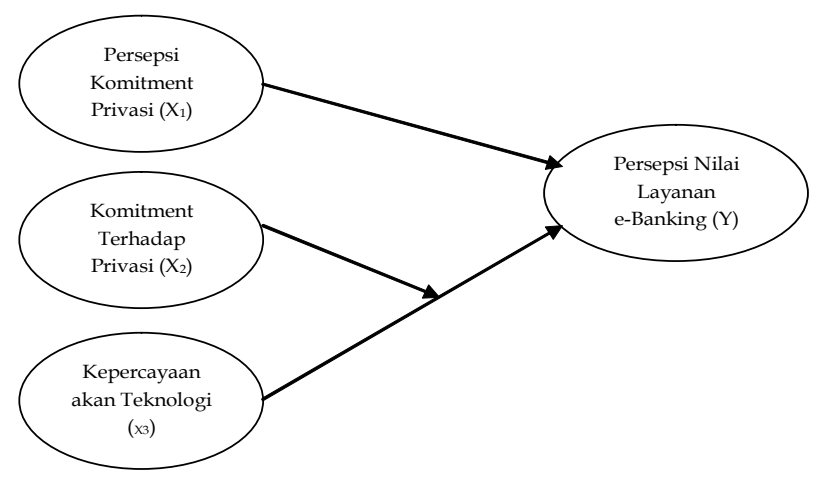

Gambar 1. Konseptual Penelitian

$Y=\alpha+\beta_{1} X_{1+} \beta_{2} X_{2+} \beta_{3} X_{3+} \beta_{4}\left(X_{2} X_{3}\right)+e \ldots \ldots \ldots$

Keterangan:

$\mathrm{Y}=$ = Persepsi Nilai

$\alpha \quad=$ Konstanta

$\beta_{1}, \beta_{2}, \beta_{3}=$ Koefisien Regresi

$\mathrm{X}_{1} \quad=$ Persepsi Komitment Privasi

$\mathrm{X}_{2} \quad=$ Dukungan Opt-out

$\mathrm{X}_{3}=$ Kepercayaan Teknologi

$\left(X_{1} X_{2}\right)=$ Interaksi antara Dukungan Opt-out dengan Kepercayaan Teknologi

e $\quad=$ Kesalahan atau standard eror
HASIL

\section{Karakteristik Responden}

Responden penelitian digambarkan secara umum dengan menyajikan karakteristiknya dilihat dari beberapa variabel demografi yaitu jenis kelamin, usia, pendidikan terakhir, pekerjaan, dan tingkat pendapatan/uang saku. Jumlah responden yang digunakan dalam penelitian ini sebanyak 120 orang. Secara rinci, karakteristik responden berdasarkan demografi disajikan pada Tabel 1.

Responden dari penelitian ini didominasi oleh jenis kelamin perempuan yaitu 93 orang $(77,5$ persen), usia 18-23 tahun sebanyak 68 orang (56,7 persen), terakhir SLTA, pekerjaan mahasiswa dengan pendapatan/uang saku $<1.000 .000 /$ bulan.

\section{Hasil Pengujian Instrumen Penelitian Uji Validitas}

Sugiyono (2013:179) menytakan suatu instrument dikatakan valid jika koefisien korelasinya (r) $>0,3$. Adapun hasil dari uji validitas ditunjukkan pada Tabel 2

Hasil uji validitas pada Tabel 2, menunjukkan bahwa seluruh variabel penelitian memiliki nilai koefisien korelasi dengan skor total seluruh item pernyataan lebih besar dari 0,3. Hal ini menunjukkan bahwa butir-butir pernyataan dalam instrumen penelitian ini adalah valid.

\subsubsection{Uji Reliabilitas}

Uji reliabilitas digunakan untuk mengukur derajat ketepatan, ketelitian suatu isntrumen. Suatu instrument dikatakan reliabel apabila nilai alpha lebih besar dari 0,6. Adapun hasil dari uji reliabilitas dapat ditunjukkan pada Tabel 3. 


\section{Dukungan Opt-Out dan Persepsi Nilai E-banking}

Ni Made Purnami

Tabel 4.1 Karakteristik Responden

\begin{tabular}{|c|c|c|c|c|}
\hline \multirow{2}{*}{ No } & \multirow{2}{*}{$\begin{array}{l}\text { Karakteristik } \\
\text { Responden }\end{array}$} & \multirow{2}{*}{ Keterangan } & \multicolumn{2}{|c|}{ Jumlah } \\
\hline & & & $\mathbf{n}$ & Persentase (\%) \\
\hline \multirow{3}{*}{1} & \multirow{2}{*}{ Jenis Kelamin } & Laki-Laki & 27 & 22,5 \\
\hline & & Perempuan & 93 & 77,5 \\
\hline & \multirow[t]{2}{*}{ Jumlah } & & 120 & 100 \\
\hline \multirow{5}{*}{2} & & 18-23 tahun & 68 & 56,7 \\
\hline & \multirow{3}{*}{ Usia } & $>23-29$ tahun & 12 & 10,0 \\
\hline & & $>29-35$ tahun & 6 & 5,0 \\
\hline & & $>35$ tahun & 34 & 28,3 \\
\hline & \multirow[t]{2}{*}{ Jumlah } & & 120 & 100 \\
\hline \multirow{5}{*}{3} & & SLTA & 59 & 49,2 \\
\hline & \multirow{3}{*}{ Pendidikan Terakhir } & Diploma & 4 & 3,3 \\
\hline & & Sarjana & 49 & 40,8 \\
\hline & & Pasca Sarjana & 8 & 6,7 \\
\hline & \multirow[t]{3}{*}{ Jumlah } & & 120 & 100 \\
\hline \multirow{6}{*}{4} & & Mahasiswa & 59 & 49,2 \\
\hline & & PNS & 34 & 28,3 \\
\hline & \multirow[t]{3}{*}{ Pekerjaan } & Pegawai Swasta & 13 & 10,8 \\
\hline & & Wiraswasta & 12 & 10,0 \\
\hline & & lainnya & 2 & 1,7 \\
\hline & \multirow[t]{2}{*}{ Jumlah } & & 120 & 100 \\
\hline \multirow{5}{*}{5} & & $\leq 1.000 .000 / \mathrm{bln}$ & 49 & 40,8 \\
\hline & \multirow{4}{*}{ Pendapatan/Uang saku } & $>1.000 .000-2.500 .000 / \mathrm{bln}$ & 23 & 19,2 \\
\hline & & $>2.500 .000-4.000 .000 / \mathrm{bln}$ & 35 & 29,2 \\
\hline & & $>4.000 .000 / \mathrm{bln}$ & 13 & 10,8 \\
\hline & & Jumlah & 120 & 100 \\
\hline
\end{tabular}

Sumber: Data Primer, diolah (2015)

Tabel 2. Hasil Uji Validitas

\begin{tabular}{|c|c|c|c|c|}
\hline No. & Variabel & Item Pernyataan & $\begin{array}{c}\text { Korelasi } \\
\text { Item Total } \\
\end{array}$ & Keterangan \\
\hline \multirow{3}{*}{1} & \multirow{3}{*}{$\begin{array}{l}\text { Persepsi } \\
\text { Komitment } \\
\text { Privasi }\left(X_{1}\right)\end{array}$} & Bank berkomitment menjaga privasi saya $\left(X_{1.1)}\right.$ & 0,822 & Valid \\
\hline & & $\begin{array}{l}\text { Bank tidak akan menyampaikan informasi pribadi saya kepada } \\
\text { perusahaan lain }\left(\mathrm{X}_{1.2}\right)\end{array}$ & 0,887 & Valid \\
\hline & & $\begin{array}{l}\text { Bank berkomitment menjaga integritas informasi pribadi saya } \\
\left(X_{1.3}\right)\end{array}$ & 0,906 & Valid \\
\hline \multirow{3}{*}{2} & \multirow{3}{*}{$\begin{array}{l}\text { Dukungan } \\
\text { Opt-out }\left(\mathrm{X}_{2}\right)\end{array}$} & $\begin{array}{l}\text { Saya bersedia informasi pribadi saya diteruskan ke perusahaan } \\
\text { lain, selama pelanggan diberi kesempatan untuk memilih keluar } \\
\text { (opt-out) ketika ada pesan promosi dari perusahaan lain }\left(X_{2.1}\right)\end{array}$ & 0,803 & Valid \\
\hline & & $\begin{array}{l}\text { Saya tidak punya masalah dengan informasi saya diteruskan ke } \\
\text { perusahaan lain, selama saya bisa untuk mengecualikan diri } \\
\text { untuk tidak dihubungi dari daftar calon konsumen oleh } \\
\text { perusahaan baru }\left(\mathrm{X}_{2.2}\right)\end{array}$ & 0,853 & Valid \\
\hline & & $\begin{array}{l}\text { Saya nyaman dengan dengan informasi pribadi saya diteruskan } \\
\text { ke perusahaan lain, asalkan saya bisa memilih keluar (opt-out) } \\
\text { ketika perusahaan baru menghubungi saya }\left(X_{2.3}\right)\end{array}$ & 0,778 & Valid \\
\hline \multirow{3}{*}{2} & \multirow{3}{*}{$\begin{array}{l}\text { Kepercayaan } \\
\text { Teknologi }\left(X_{3}\right)\end{array}$} & Saya nyaman menggunakan smartphone dalam bertransaksi $\left(\mathrm{X}_{3.1)}\right.$ & 0,739 & Valid \\
\hline & & Saya percaya bahwa, kesalahan transaksi online langka $\left(\mathrm{X}_{3.2}\right)$ & 0,881 & Valid \\
\hline & & Menurut pendapat saya, teknologi smartphone sangat handal $\left(\mathrm{X}_{3.3}\right)$ & 0,859 & Valid \\
\hline \multirow{3}{*}{2} & \multirow{3}{*}{$\begin{array}{l}\text { Persepsi Nilai } \\
(Y)\end{array}$} & $\begin{array}{l}\text { Biaya yang saya keluarkan dalam menggunakan e-banking sesuai } \\
\text { dengan layanan yang diberikan }\left(\mathrm{Y}_{1}\right)\end{array}$ & 0,767 & Valid \\
\hline & & Penggunaan $e$-banking menghemat waktu berbelanja $\left(\mathrm{Y}_{2}\right)$ & 0,738 & Valid \\
\hline & & $\begin{array}{l}\text { Secara keseluruhan penggunaan e-banking memberikan manfaat } \\
\text { bagi saya }\left(\mathrm{Y}_{3}\right)\end{array}$ & 0,762 & Valid \\
\hline
\end{tabular}


Tabel 3. Hasil Uji Reliabilitas

\begin{tabular}{clcc}
\hline No. & \multicolumn{1}{c}{ Variabel } & Cronbach's Alpha & Keterangan \\
\hline 1 & Persepsi Komitment Privasi $\left(\mathrm{X}_{1}\right)$ & 0,819 & Reliabel \\
2 & Dukungan Opt-out $\left(\mathrm{X}_{2}\right)$ & 0,741 & Reliabel \\
3 & Kepercayaan Teknologi $\left(\mathrm{X}_{3}\right)$ & 0,770 & Reliabel \\
4 & Persepsi Nilai $(\mathrm{Y})$ & 0,618 & Reliabel \\
\hline
\end{tabular}

Sumber: Data Primer, diolah (2015)

Tabel 4. Hasil Moderated Regression Analysis (MRA)

\begin{tabular}{|c|c|c|c|c|c|}
\hline \multirow[t]{2}{*}{ Variabel } & \multicolumn{2}{|c|}{ Unstandarized } & \multirow{2}{*}{$\begin{array}{c}\begin{array}{c}\text { Standarized } \\
\text { Coeficients }\end{array} \\
\text { Beta } \\
\end{array}$} & \multirow[t]{2}{*}{$\mathbf{t}$} & \multirow[t]{2}{*}{ Sig. } \\
\hline & B & Std Error & & & \\
\hline (Constant) & 0,057 & 0,059 & & 0,967 & 0,336 \\
\hline $\begin{array}{l}\text { Persepsi Komitment Privasi } \\
\left(X_{1}\right)\end{array}$ & 0,137 & 0,066 & 0,137 & 2,091 & 0,039 \\
\hline Dukungan Opt-out $\left(\mathrm{X}_{2}\right)$ & 0,282 & 0,061 & 0,282 & 4,644 & 0,000 \\
\hline Kepercayaan Teknologi (X3) & 0,529 & 0,067 & 0,529 & 7,926 & 0,000 \\
\hline Interaksi $\left(\mathrm{X}_{2} \mathrm{X}_{3}\right)$ & $-0,153$ & 0,060 & $-0,144$ & $-2,561$ & 0,012 \\
\hline Adjusted $\mathbf{R}^{2}$ & & & & & 0,637 \\
\hline F Hitung & & & & & 53,237 \\
\hline Sig. F & & & & & 0,000 \\
\hline
\end{tabular}

Sumber: Hasil Pengolahan data Penelitian, 2015

Pada Tabel 2 menunjukkan bahwa masingmasing nilai Cronbach's Alpha untuk setiap variabel lebih besar dari 0,6. Hal tersebut menunjukkan bahwa keempat variabel adalag reliabel sehingga dapat digunakan untuk analisis selanjutnya.

Analisis kelayakan model (Uji F) pada Tabel 4 menunjukkan nilai F hitung sebesar 53,237 dengan nilai signifikansi sebesar 0,000. Nilai signifikansi tersebut lebih kecil dari alpha 0,05 yang menunjukkan bahwa interaksi dukungan opt-out dan kepercayaan teknologi secara bersama-sama berpengaruh pada persepsi nilai $e$-banking. Nilai Adjusted $R^{2}$ sebesar 0,637 berarti 63,7 persen variasi persepsi nilai e-banking dapat dijelaskan oleh variasi persepsi komitment privasi, dukungan opt-out, kepercayaan teknologi dan interaksi interaksi keyakinan optout dan kepercayaan teknologi, sedangkan sisanya (36,3 persen) dijelaskan oleh faktor-faktor lain di luar model. Berdasarkan hasil Moderated Regression Analysis (MRA) pada Tabel 4 maka persamaan yang sesuai dengan model penelitian ini dapat disusun sebagai berikut:

$$
\begin{aligned}
Y= & 0,057+0,137 X_{1}+0,282 X_{2}+0,529 X_{3}-0,153\left(X_{2} X_{3}\right) \\
& +e \ldots \ldots \ldots \ldots \ldots \ldots \ldots \ldots \ldots \ldots \ldots \ldots
\end{aligned}
$$

Pengaruh secara parsial variabel persepsi komitment privasi, keyakinan opt-out, kepercayaan teknologi, serta peran dukungan opout dalam memoderasi pengaruh kepercayaan teknologi terhadap persepsi nilai dapat dilihat pada Tabel 4. Pertama, nilai koefisien regresi parsial variabel persepsi komitment privasi sebesar 0,137 dengan tingkat signifikansi sebesar 0,039 $(<0,05)$. Hal ini mengindikasikan bahwa persepsi komitmen privasi berpengaruh positif dan signifikan pada persepsi nilai $e$-banking, sehingga hipotesis pertama diterima. Oleh karena itu, bila komitmen privasi bank semakin tinggi dalam melindungi nasabah, maka persepsi nilai e-banking akan semakin meningkat. Kedua, nilai koefisien regresi parsial variabel 
keyakinan opt-out sebesar 0,282 dengan tingkat signifikansi sebesar 0,000 $(<0,05)$. Hal ini mengindikasikan bahwa dukungan opt-out berpengaruh positif pada persepsi nilai. Hasil ini menunjukkan bahwa semakin tinggi keyakinan opt-out seseorang, maka persepsi nilai terhadap layanan $e$-banking akan semakin meningkat. Ketiga, nilai koefisien regresi parsial variabel kepercayaan teknologi sebesar 0,529 dengan tingkat signifikansi sebesar 0,000 (< $0,05)$. Hal ini mengindikasikan bahwa kepercayaan teknologi berpengaruh positif dan signifikan pada persepsi nilai e-banking, sehingga hipotesis kedua diterima. Penelitian ini memberikan kontribusi kepada bank yang menyediakan layanan e-banking agar senantiasa berkomitment menjaga privasi konsumennya dengan tidak menyebarluaskan informasi pribadi konsumen kepada pihak lain untuk tujuan komersial untuk meningkatkan persepsi nilai yang diterima konsumen yang pada akhirnya akan menciptakan loyalitas.

Dukungan opt-out menjadi variabel pemoderasi karena nilai alpha $=0,012(<0,05)$. Dukungan opt-out tampak berperan sebagai variabel pemoderasi yang memperlemah pengaruh kepercayaan teknologi pada persepsi nilai e-banking. Pada Tabel 4 dapat dilihat bahwa variabel interaksi $\left(X_{2} X_{3}\right)$ memberikan nilai koefisien parameter sebesar 0,153 dengan tingkat signifikansi $0,012(<0,05)$. Oleh karena variabel interaksi $\left(\mathrm{X}_{2} \mathrm{X}_{3}\right)$ merupakan interaksi antara dukungan opt out dengan kepercayaan teknologi menunjukkan tanda negatif, maka dapat dikatakan bahwa Keyakinan opt-out merupakan variabel pemoderasi yang memperlemah hubungan kedua variabel tersebut. Hal ini berarti apabila kepercayaan teknologi yang dimiliki seseorang semakin positif dalam melakukan transaksi dengan layanan e-banking dan didukung dukungan opt-out, maka hal ini akan mempengaruhi persepsi nilai terhadap layanan e-banking semakin menurun. Hasil penelitian ini menunjukkan bahwa nasabah yang menggunakan layanan e-banking memiliki tingkat keyakinan yang rendah dalam opt out dari email marketing dimana dapat juga dikatakan bahwa nasabah dalam penelitian ini tidak bersedia informasi pribadi mereka diteruskan ke pihak ketiga tanpa meminta ijin sebelumnya.

\section{SIMPULAN DAN SARAN}

Persepsi komitmen privasi berpengaruh positif dan signifikan pada persepsi nilai e-banking. Oleh karena itu, bila persepsi komitment privasi bank dalam menjaga informasi pribadi nasabah semakin positif atau semakin baik, maka persepsi nilai terhadap layanan e-banking juga akan meningkat. Kepercayaan teknologi berpengaruh positif dan signifikan pada persepsi nilai e-banking, sehingga semakin tinggi tingkat kepercayaan terhadap teknologi maka persepsi nilai terhadap layanan e-banking juga meningkat. Dukungan optout merupakan variabel pemoderasi yang memperlemah hubungan variabel kepercayaan teknologi dan persepsi nilai.

Saran yang dapat diberikan bagi bank yang memberikan layanan e-banking agar senantiasa berkomitment menjaga privasi konsumennya dengan tidak menyebarluaskan informasi pribadi konsumen kepada pihak lain untuk meningkatkan persepsi nilai yang diterima konsumen yang pada akhirnya akan menciptakan loyalitas. Saran bagi peneliti selanjutnya adalah mengembangkan model penelitian dengan menambahkan variabel lain seperti kepuasan nasabah dan loyalitas nasabah.

\section{DAFTAR PUSTAKA}

Armesh, H., Salarsehi, H., Yaghooby, N.M., Heydari, Alireza \& Nikbin, Davound. 2010. The Effects of Security and Privacy Information on Trust \& Trustworthiness and Loyalty in Online Marketing in Malaysia. International Journal of Marketing Studies, 2(2):223-234

Benedicktus, R.L., Brady, M.K., Darke, P.R \& Voorhees, C.M. 2010. Conveying Trustworthiness to Online Consumers: Reactions to Consensus, Physical Store Presence, Brand Familiarity, and Generalized Suspicion. Journal of Retailing, 86 (4): 322-335 


\section{Jurnal Keuangan dan Perbankan | PERBANKAN}

Vol. 19, No.3, September 2015: 497-504

Carlson, J., \& O'Cass, A. 2011. Developing a framework for Understanding E-Service Quality, Its Antecedents, Consequences, and Mediators. Managing Service Quality, 21(3): 264-286.

Chen, T. 2011. Personality Traits Hierarchy of Online Shoppers. International Journal of Marketing Studies, 3(4): 23-39

Chen, Yen-Ting \& Chou, Tsung-Yu. 2012. Exploring the Continuance Intentions of Cunsumer for B2C Online Shopping. Online Information Review, 26 (1): 104-125.

Chi, H., Yeh, H., \& Hung, W. (2012). The Moderating Effect of Subjective Norm on Cloud Computing Users' Perceived Risk and Usage Intention. International Journal of Marketing Studies, 4(6): 95-10

Craig, V. S., Shim, J. T., Johnson, R., \& Jiang, J. 2006. Concern for information privacy and online consumer Purchasing. Journal of the Association for Information Systems, 7(6)

Dimitriadis, S., \& Kyrezis, N. 2011. The Effect Of Trust, Channel Technology, And Transaction Type On The Adoption Of Self-Service Bank Channels. Service Industries Journal, 31(8): 1293-131

Dinev, T., Xu, Heng., Smith, J.H \& Hart, Paul. 2013. Information privacy and correlates: An Empirical Attempt To Bridge And Distinguish Privacy-Related Concepts, European Journal of Information Systems, 22: $295-316$

Ghozali, Imam. 2014. Struktural Equation Modeling. Metode Alternatif dengan Partial Least Squares (PLS). Universitas Diponegoro: Semarang

Grabner, Kra“uter, S \& Faullant, Rita. 2008. Consumer Acceptance Of Internet Banking: The Influence Of Internet Trust. International Journal of Bank Marketing, 26 (7): 483-504

Johnson, Devon S. 2014. Opting Out: The Effects of Consumer Information Sharing Concerns on Perceived Value in E-Banking Relationships. Internation Journal of marketing Studies, Vol. 6 (2): 1-11

Kesharwani, Ankit and Bisht, Shailendra S. 2012. The Impact of Trust and Perceived Risk on Internet Banking Adoption in India. International Journal of Bank Marketing, 30 (4): 303-322
Ketkar, SP; Shankar, Ravy and Banwet, DK. 2012. Structural Modeling and Mapping of M-banking Influencers in India. Journal of Electronic Commerce Research, 13 (1): Pp. 70-87

Kotler, Philip., Armstrong, Gary. 2008. Prinsip-Prinsip Pemasaran. Erlangga: Jakarta

Liu, Y. (2003). Developing a scale to measure the interactivity of websites. Journal of Advertising Research, 43(2):207-216.

Liu, Heng Yih \& Hung, Wei Tien.2010. Online Store Trustworthiness And Customer Loyalty:Moderating The Effect Of The Customer' $S$ Perception Of The Virtual Environment. African Journal of Business Management, 4(14): 2915-2920

McMillan, S. J., \& Hwang, J. (2002). Measures of perceived interactivity: An exploration of the role of direction of communication, user control, and time in shaping perceptions of interactivity. Journal of Advertising, 31(3): 29-42

Porter, C. E., \& Donthu, N. (2008). Cultivating trust and harvesting value in virtual communities. Management Science, 54(1), 113-128

Thatcher, J. B., Loughry, M. L., Lim, J., \& McKnight, H. D. (2007). Internet Anxiety: An Empirical Study Of The Effects Of Personality, Concerns, And Social Support. Information \& Management, 44(4): 353-363

Sugiyono. 2013. Statistika Untuk Penelitian. Bandung: Alfabeta.

Wen, Chao., Prybutok, Victor R., Xu, Chenyan. 2011. An Integrated Model for Customer Online repurchase Intention. Journal of Computer Information System. Pp. 14-23.

Yao, C., \& Liao, S. 2011. Measuring The Antecedent Effects Of Service Cognition And Internet Shopping Anxiety on Consumer Satisfaction With E-Tailing Service. Management $\mathcal{E}$ Marketing, 6(1): 59-78

Yap, Kenneth B; Wong, Davis H; Loh, Claire and Bak, Randall. Offline And Online Banking -Where To Draw The Line When Building Trust In E-Banking?. International Journal of BankMarketing, 28 (1): 27-46 